F. med. Genet. (1966). 3, 285 .

\title{
Symphalangism
}

\section{A Pedigree from South India}

\author{
GEMMA SAVARINATHAN and WILLARD R. CENTERWALL
}

\section{From the Department of Paediatrics, Christian Medical College and Hospital, Vellore, S. India}

First reported in 1890 by Benario and by Sklodowski, the condition of bony or fibrous ankylosis of the phalangeal joints was designated 'symphalangism' by Cushing in 1916. By then, however, symphalangism had already acquired a unique position in the annals of genetic writing, for in 1908 Drinkwater reported the condition in the I2th, I3th, and I4th generation, direct descendants of John Talbot, the Ist Earl of Shrewsbury who was born in 1390 . In 1874 the Earl's skeleton was exhumed and bony fusion of the phalanges of the two index fingers was noted, thus establishing one of the longest records of transmission of a specific, anatomical abnormality.

Symphalangism has been shown to follow a simple Mendelian dominant pattern with both male and female about equally affected. Usually it has been found as an isolated defect but also has been known to be associated with other anomalies such as brachydactyly (Bell, 1951), deficiency of pectoralis muscles (Benario, I890; Sklodowski, I890), deafness and strabismus (Vesell, 1960), and polydactyly and syndactyly (Bunnel, 1956).

Polydactyly and syndactyly are probably the most common of all hand and foot anomalies, with nearly one in every thousand babies born being involved with one or the other (or both) of these defects (Mercer, 1959; Lamy and Frézal, 196I). As with the less common symphalangism these anomalies appear to have a dominant mode of inheritance and are usually isolated findings. Sometimes, however, they are associated variably with other congenital abnormalities as in the Laurence-Moon-Biedl and Ellis-van Creveld syndromes, acrocephalosyndactyly, DI (13-15) trisomy, symphalangism, and other affections.

So far as we know, symphalangism has been reported only in the West with more than 245 cases (in about a dozen pedigrees) having been described there by the mid-century (Bell, 1951; Vesell, 1960).

Received May 7, 1966.
Symphalangism usually involves the proximal, interphalangeal joints of the second, third, and fourth fingers. The toes may also be affected. However, the thumbs are almost never involved and the fifth fingers infrequently (Freud and Slobody, 1943).

This is a report of a South Indian family, in which some of the affected members showed fibrous symphalangism in otherwise normal-appearing thumbs, either one or both, and which was associated with polydactyly and syndactyly. In some of the abnormal extra digits a bony and in others a fibrous symphalangism was noted. Other members of this family presented with variable polydactyly and syndactyly.

\section{Case Reports}

The family are Hindus of the Harijan Community and have lived in a small village near Vellore, Madras State, for generations. The nine, living, affected persons were all examined; three reputedly affected persons, I.3, II.I, and III.3 had died (Fig. I).

Case 1 (III.13). Propositus (Fig. 2 a-d). This 35-year-old woman presented with (a) symphalangism, with only very slight movement of the interphalangeal joints of both otherwise normal-appearing thumbs, with absent cutaneous flexion creases at those joints-also a rigid bony symphalangism of the extra non-functional sixth fingers and second toes bilaterally, and the most lateral (abnormal) toe of the right foot; (b) polydactyly with six digits on both hands and seven digits on both feet, and (c) syndactyly between the fourth and fifth fingers of the left hand and between the fifth, sixth, and seventh toes of both feet. Radiographs showed minimal incomplete splitting of the distal phalanges of the thumbs and fifth fingers bilaterally, and bony fusion of the phalanges of the abnormal sixth fingers bilaterally and the sixth-seventh toe complex of the right foot.

Case 2 (IV.r3). (Fig. 3 a-d). This r2-year-old daughter of the propositus presented with (a) symphalangism, similar to that of her mother, of the interphalangeal joint of the left thumb, with an absent cutaneous skin crease at that joint, and a symphalangism also with only slight movement possible in the non- 


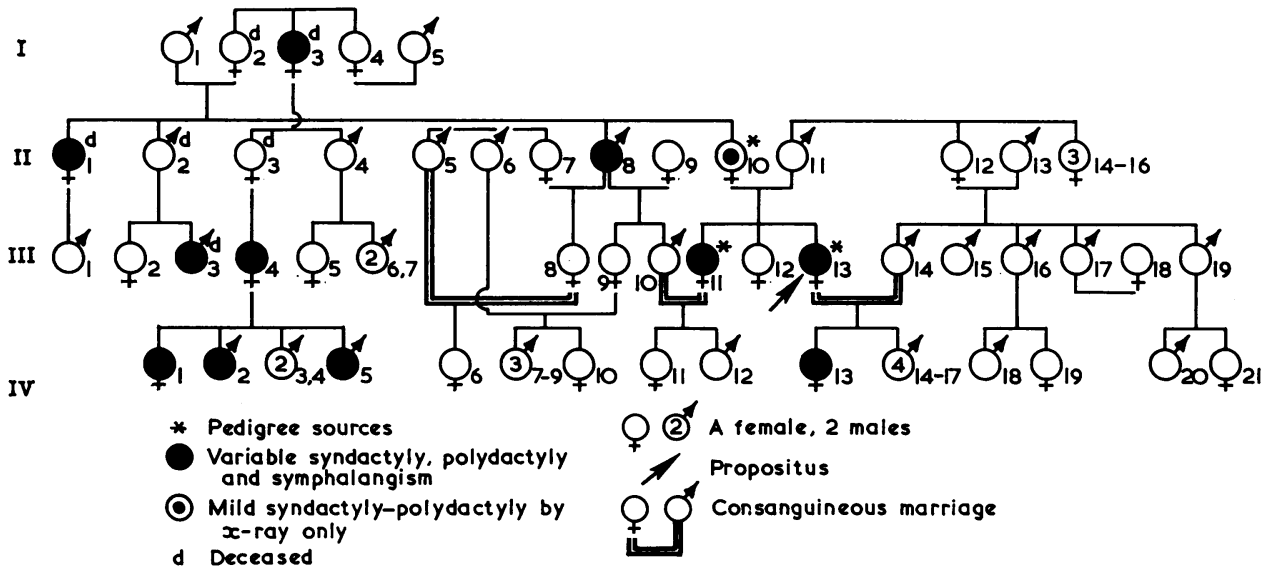

FIG. I. Pedigree of the family described.
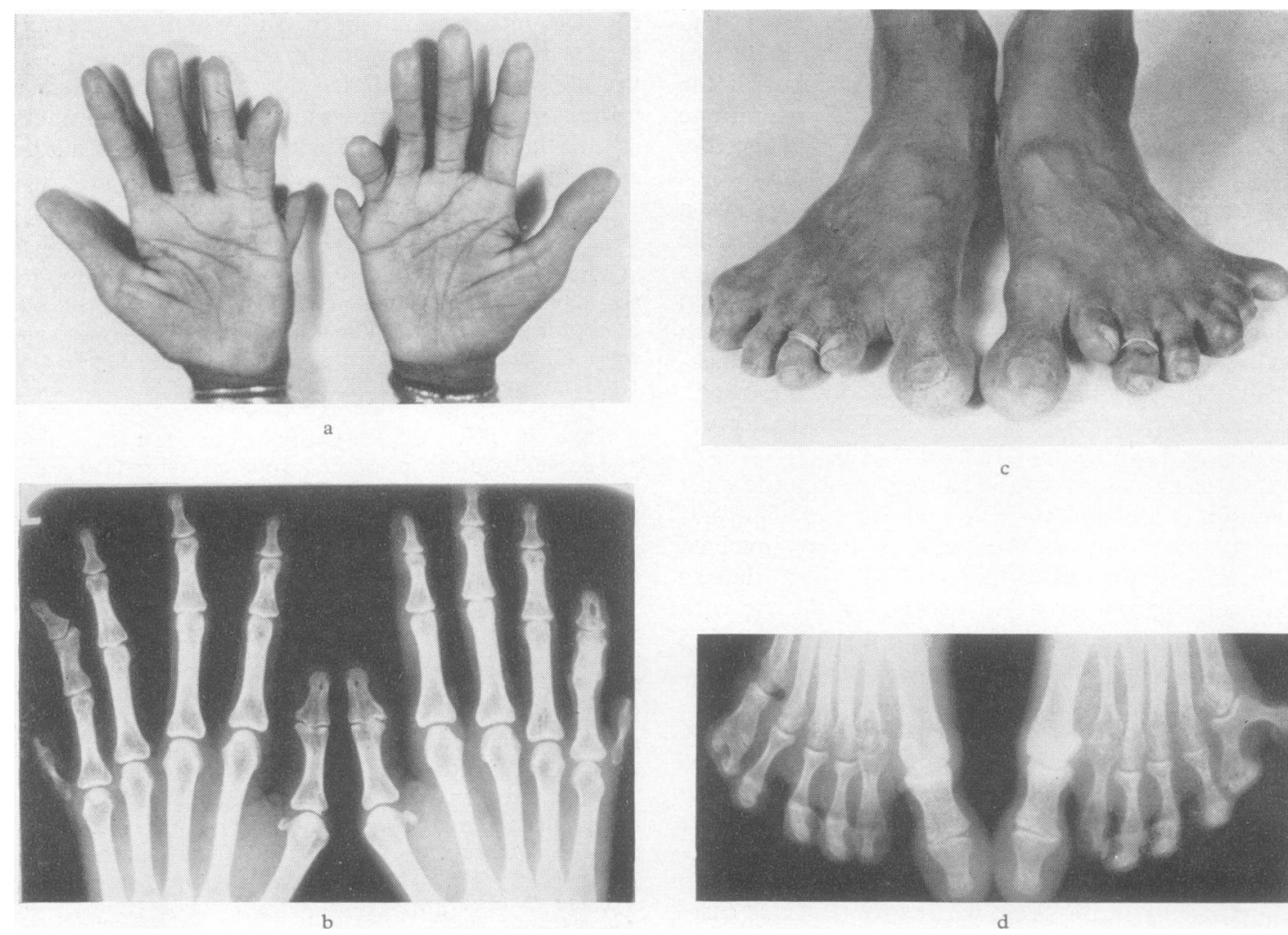

FIg. 2a-d. Appearances in propositus, Case I (III.13). In FIG. 2b rings on the third toe indicate that she is married. Normally they are placed on second toe, but in this case the non-functional extra toe was avoided. 

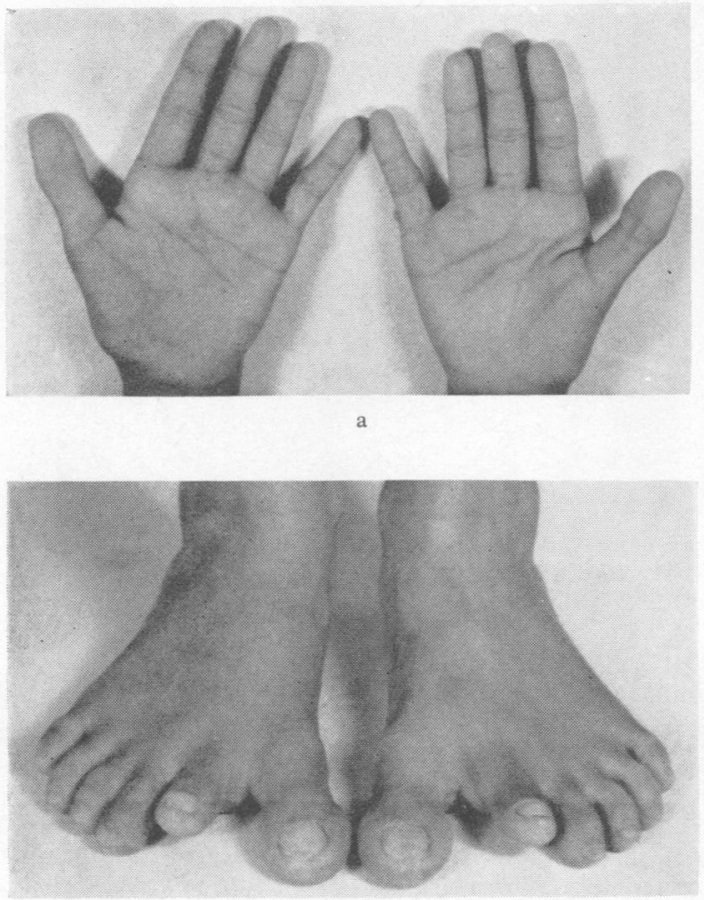

FIG. 3a-d. Appearances in propositus's daughter, Case 2 (IV.13). In FIG. 3a note a small surgical scar on the ulnar aspect of the right hand, which indicates where a sixth finger had been. In this area of South India, people often prefer not to remove even an easily operable extra digit, in the belief that it is a good omen.

functional, extra, second toes of each foot; (b) polydactyly with six digits of the right hand (surgical scar remains) and six digits on both feet, the extra toe being between the normal first and second toes. Radiographs showed minimal incomplete splitting of the distal phalanges of the thumbs bilaterally.

Case 3 (II.ro). (Fig. $4 \mathrm{a}$ and b). This 55-year-old mother of the propositus had normal-appearing and normal-functioning hands and feet. With the seeming dominant mode of inheritance, this lady should have been involved with the syndrome. Radiographs of her hands and feet were taken, and bilateral mild incomplete splitting of the distal phalanges of the thumbs was demonstrated.

Case 4 (II.8). This 45-year-old uncle of the propositus presented with (a) fibrous symphalangism of the interphalangeal joints of both thumbs with absent cutaneous skin creases at those joints, (b) six-digit polydactyly of both hands, and (c) syndactyly of the first and second toes of the right foot. Radiographs showed mild splitting of the distal phalanges of both thumbs similar to that observed in the preceding three cases.
Case 5 (III.I I). This 30-year-old sister of the propositus presented with (a) a rudimentary, six-digit polydactyly of the right foot, and (b) syndactyly of the same foot between the normal first toe and the extra digit on its medial side. Radiographs showed that the rudimentary 'toe' resulted from a complete splitting and separation of the distal phalange of the right big toe.

Case 6 (III.4). This 45-year-old woman, a second cousin of the propositus, presented with (a) polydactyly of six digits on both hands and (b) syndactyly of the second and third toes of both feet.

Case 7 (IV.I). This I4-year-old daughter of the above lady presented with syndactyly between the fourth and fifth fingers of both hands and between the first and second toes of both feet.

Case 8 (IV.2). This 7-year-old brother of the above presented with (a) six-digit polydactyly of both hands, (b) a syndactyly between the third and fourth fingers of the right hand, between the third, fourth, and fifth fingers of the left hand, and between the first, second, and third toes of both feet. Unsuspected clinically, radiographs showed a complete splitting and separation of the distal phalanges of the big toes of both feet. 

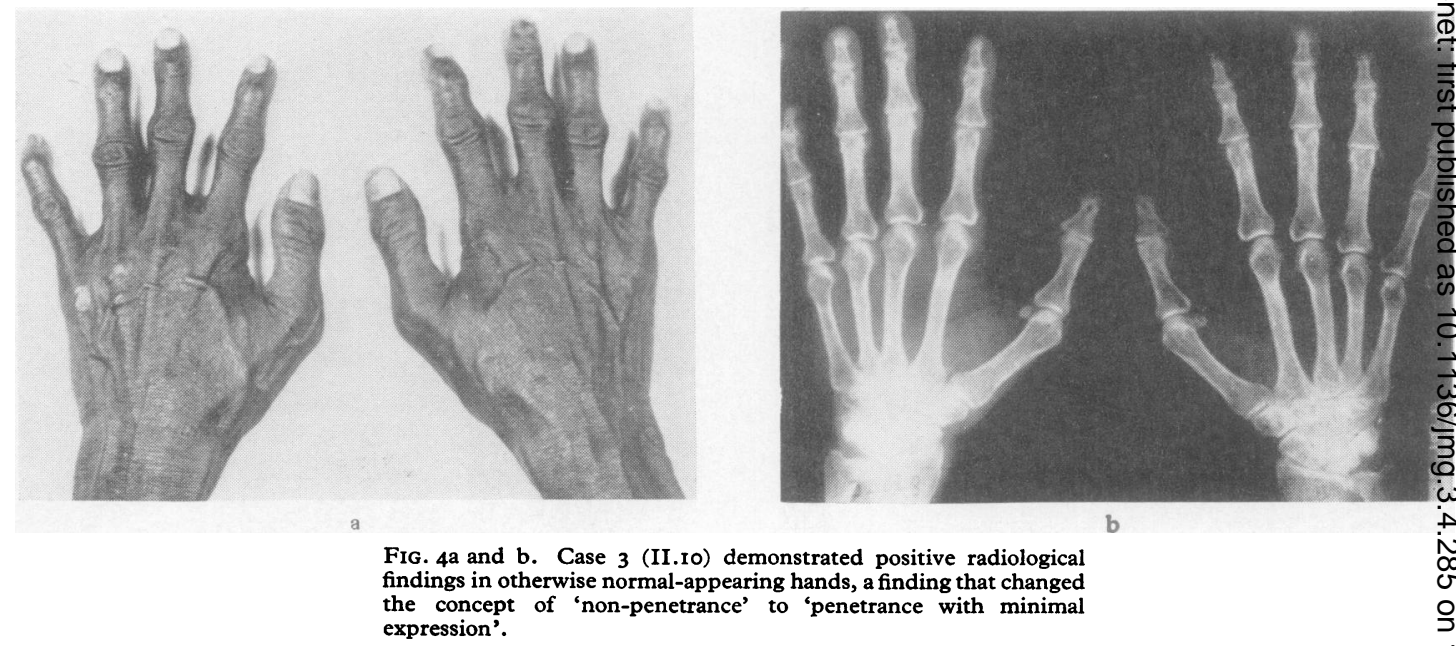

Case 9 (IV.5). This 3-year-old brother of the above presented with syndactyly of the first and second toes of both feet. Unsuspected clinically, radiographs showed complete splitting and separation of the distal phalange of the first toe of the right foot.

Apart from these nine observed cases, there is hearsay evidence of three further members of the family.

I.3, a great-aunt of the propositus, was said to have had a six-digit polydactyly of both hands.

II.I, a maternal aunt of the propositus, was said to have had syndactyly of the first and second toes of the right foot.

III.3, a first cousin of the propositus, was said to have had polydactyly of both hands and both feet.

All cases of syndactyly of the hands consisted of a thin, cutaneous web between the fingers, whereas in the case of the feet it was either a fleshy or a bony syndactyly. There were 4 instances (Cases $2,4,6$, and 8 ) where it was discovered that the extra small digits on the hands had been removed, with only surgical scars remaining. In all cases of polydactyly of the hands, the extra fingers arose from the ulnar sides of the hands. The 3 persons (Cases I, 2, and 4) with thumb symphalangism were able to move the affected joints slightly, a finding consistent with fibrous as opposed to bony ankylosis. Bony symphalangism, by physical examination and by radiograph, was confined to some abnormal extra digits of the hands and feet.

The father and the other children of the propositus, the remaining children of Case 6 (III.4), and the children and grand-children of Case 4 (II.8) were also examined and were found to possess no clinical abnormalities of the fingers or toes; $x$-ray photographs were not taken.

\section{Discussion}

The family tree covers four generations and is representative of a typical, South-Indian, Hindu family pedigree, showing some common types of consanguineous marriage found in this part of the world (Centerwall, 1964).

Clinical Aspects. In all five instances (in three persons) of thumb symphalangism, the radiographs revealed well-developed joint cavities suggesting a fibrous rather than a bony ankylosis. This was borne out clinically by the slight movemen possible in these joints. It is interesting to note that the symphalangism affected only the interphalangea joints of otherwise normal-appearing thumbs and several of the abnormal extra digits of the hands and feet (bony and fibrous ankylosis). In symphalang 3 ism, as reported in the West, the thumbs are rare臣 involved. There was no known history of symp phalangism in any of the family members who hat not been examined. However, it is possible that thes digital anomaly might have passed unnoticed be cause of its relative insignificance. That this appears. to be the first report of symphalangism to come ouf of India does not necessarily mean that the affection is rare here or that the manifestations are somewh different from those seen in the West.

Pathology. The pathology of symphalangisi has been ascribed by Cushing (1916) to the apo pearance of ossification centres in the proximab phalangeal row later than in the distal row. Freus and Slobody (1943) felt they could demonstrafe radiologically that symphalangism was due to the failure of differentiation of an interphalangeal joir during the embryonic stage. In the present repord fibrous symphalangism of the five involved thumbs was always associated with minimal incomplete splitting of the distal phalanges (an incomplet 
polydactyly and bony syndactyly). This suggests that this arrested abnormal division also involved the fibrous structures about the adjacent joints, with resultant symphalangism; that is to say, in this pedigree, symphalangism, bony syndactyly, and polydactyly are probably part of the same process. Other fingers with similar minimal phalangeal splitting, however, showed no symphalangism nor was symphalangism found in all instances with such radiological findings in the thumbs. This suggests, in this pedigree, a selective but not consistent, thumb susceptibility to fibrous symphalangism. Apparent fibrous ankylosis of non-functional extra toes (Case 2 (IV.I3)) could possibly be explained on the basis of disuse stiffness. However, the clinical and $x$-ray evidence of bony symphalangism in certain other extra digits (Case I (III.I3), Fig. 2a-d) indicates a congenital origin tying abnormal embryology with this bony fusion. The simple webbing of the fingers and toes which occurs in some members of the family represents an arrest of normal division at an embryonic level. It would not be unreasonable to assume that all the various 'divisionand-arrest' limb anomalies observed in this pedigree are the result of a specific enzymatic defect acting adversely at a crucial period in embryonic life.

Mode of Inheritance. The frequent occurrence in successive generations of this anomalous condition, which involves both males and females, suggests an autosomal dominant form of inheritance. Apparently symphalangism, as reported in the West, has been almost completely penetrant (Elkin, 1925). The failure in our pedigree to follow consistently a direct line of inheritance suggests low penetrance, but radiographs of the clinically and functionally normal hands and feet of a direct-line descendant (Case 3 ; II. Io) revealed minimal, incomplete splitting of the distal phalanges of the thumbs, i.e. there was incomplete expression rather than non-penetrance. It was unfortunate that the two other direct-line-ofdescent persons in whom no digital abnormalities were noticed (I.2 and II.3) had died so were not available for physical or radiological examination.

The three persons with symphalangism had an associated polydactyly and syndactyly (syndactyly only evident by radiograph in one case). All the other affected members had varying degrees of involvement with polydactyly and/or syndactyly. This pattern is best explained by the concept of a single autosomal dominant pleiotropic gene with variable expression.

\section{Summary}

A family tree with symphalangism, polydactyly, and syndactyly is reported for the first time from India. The symphalangism consisted of a fibrous ankylosis involving the interphalangeal joints of otherwise apparently normal thumbs and a bony ankylosis of several, extra, non-functional digits. Some aspects of pathogenesis and the likely mode of inheritance are discussed.

We are obliged for the photographs to Mr S. D. Sigamony and the pedigree to Mr V. N. Guiry, of the Christian Medical College Hospital, Vellore, South India.

\section{REFERENCES}

Bell, J. (I95I). On hereditary digital anomalies. Part I. On brachydactyly and symphalangism. Treas. hum. Inher., 5, I.

Benario, J. (1890). Ueber einen Fall von angeborenen mangel des musculus pectoralis major und minor mit Flughautbildung und Schwimmhautbildung. Berl. klin. Wschr., 27, 225.

Bunnel, S. (1956). Surgery of the Hand, 3rd ed., p. 939. Pitman, London.

Centerwall, W. R. (1964). A Preliminary Report on Consanguinity and Congenital Anomalies in South India, presented at the Second Afro-Asian Congress of Pediatrics in Jakarta, Aug. 19-27, 1964, to be published in Pediatrica indonesiana.

Cushing, H. (I9I6). Hereditary ankylosis of the proximal phalangeal joints. Genetics, r, 90.

Drinkwater, H. (1908). An account of a brachydactylous family. Proc. roy. Soc. Edinb., 28, 35.

Elkin, D. C. (1925). Hereditary ankylosis of the proximal phalangeal joints. F. Amer. med. Ass., 84, so9.

Freud, P., and Slobody, L. B. (I943). Symphalangism, a familial malformation. Amer. F. Dis. Child., 65, 550.

Lamy, M., and Frézal, J. (196I). The frequency of congenital malformations. In First International Conference on Congenital Malformations, Papers E Discussions, pp. 34-44. J. B. Lippincott, Philadelphia \& Montreal.

Mercer, W. (1959). Orthopaedic Surgery, 5th ed., p. 93. Edward Arnold, London.

Sklodowski, J. (1890). Ueber einen Fall von angebornem rechtsseitigen mangel der musculi pectorales major et minor mit gleithzeitigen missbildungen der rechten Hand. Virchows Arch. path. Anat., 121, 600.

Vesell, E. S. (1960). Symphalangism, strabismus and hearing loss in mother and daughter. New Engl. F. Med., 263, 839. 